\title{
The atmospheric boundary layer
}

\section{Special issue honouring the memory of Hans Hinzpeter}

\author{
By ANDREas Chlond* and Hartmut GRASSL \\ Max Planck Institute for Meteorology, Hamburg, Germany
}

The colloquium on "The atmospheric boundary layer" was held in Hamburg from February 12 to 13, 2001 and was organized by the Max Planck Institute for Meteorology in cooperation with the Meteorological Institute of the University of Hamburg. The event was organised to honour the memory of Prof. Dr. Hans Hinzpeter, distinguished meteorologist, teacher, administrator and science policy maker. Prof. Hinzpeter was the former director of the Meteorological Institute of the University of Hamburg and director at the Max Planck Institute for Meteorology. The colloquium was held on the occasion of the first anniversary of his death (December 15, 1999) and of his 80th birthday (January 31, 2001). Although Prof. Hinzpeter's range of interests was legendary, the colloquium focused on the atmospheric boundary layer because during Hinzpeter's era in Hamburg the understanding of convective and turbulent processes in the marine boundary layer was substantially pushed as a result of the numerous field experiments organised by himself. The aim of the colloquium was to give, on the basis of recent observational and modelling studies, an overview of the advances in the level of knowledge of clear and cloudy boundary layers, as provided by former students and close collaborators of Hans Hinzpeter.

During the last decades major efforts went into the understanding of the atmospheric boundary layer. Initially much emphasis was given on the clear convective and shear driven boundary layer and studies were predominantly concerned with questions of how much momentum, heat, moisture and air pollutants are transported by turbulent motions and how do these turbulent eddies interact with each other and with the thermal inversion which is capping the atmospheric boundary layer. A better fundamental understanding of these questions became even more relevant for a cloudy atmospheric boundary layer. Therefore, in the last decade the field has expanded with numerous studies on turbulence and boundary layer clouds on different scales. These studies have provided updated theories and concepts, through the combined efforts of observational campaigns, high-resolution modelling, evaluation and impact studies. From a practical perspective, a better understanding of turbulence in the atmospheric boundary layer had served to improve the parameterisation of boundary-layer processes in large-scale climate and weather prediction models.

The special issue is organised in three parts. Part 1 contains a historical review focusing on different steps of the professional career of Prof. Hinzpeter. Part 2 covers five papers on observational studies utilizing in-situ instruments as well as remote sensing devices like lidar, radar and sodar in order to study the mean state and turbulence structure of the boundary layer. Part 3 contains three papers on modelling studies ranging from a small-scale large-eddy simulation of the cloud-topped boundary layer to the application of boundary layer knowledge for meso-scale modelling including environmental and air-quality research issues.

Finally, we would like to thank all the speakers and participants at the meeting for their contributions and suggestions. We also thank the Max Planck Society for the financial support to the colloquium which also allowed an effective exchange of ideas and interaction among experimentalists and modellers working on various aspects of the atmospheric boundary layer.

${ }^{*}$ Corresponding author: Andreas Chlond, Max Planck Institute for Meteorology, Bundesstraße 55, 20146 Hamburg, Germany, e-mail: chlond@dkrz.de 
BLANK PAGE 